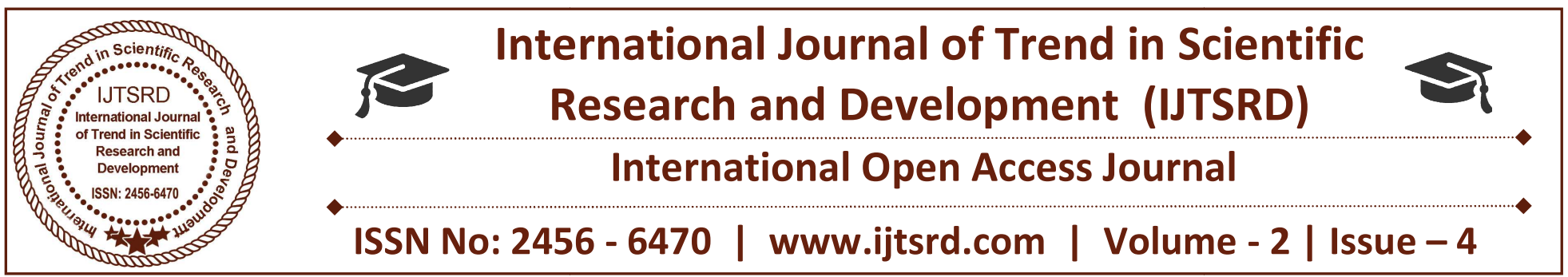

\title{
Modelling and Simulation of Grid-Connected Solar-Hydro based Hybrid Power System
}

\author{
Karan Sapotra \\ M.Tech Scholar, Electrical Engineering Department, \\ Yamuna Institute of Engineering \& Technology, Gadhauli, Yamunanagar, Haryana, India
}

\section{ABSTRACT}

In this paper DC linked, grid connected solar/hydro hybrid system is modelled and simulated. A control scheme is developed for solar and hydro system for variable solar irradiance and variable load. Synchronous generator based hydro system is used to feed bulk of the power and whenever solar irradiance is available solar system along with hydro system and grid supply to the load. The performance analysis of the proposed HES and its power management strategy has been done using the simulink toolboxes of MATLAB software. The proposed system consists PV system hydro system, battery and grid. In some remote/rural areas, it is very difficult to satisfy the demand of electrical power throughout the year with the power grid. In such areas, the power requirement can be fulfilled by renewable energy system such as hydro or PV system. Either the hydro system or PV system is not capable of supplying power requirement throughout the year as both systems are intermittent. Hence, the judicious combination of hydro and PV system has been modeled for electrification. The power management strategy is modeled to manage the power flow of the energy systems to fulfill the load demand. The presented results clearly show that the proposed HES and its control strategy are suitable for implementation in remote/rural areas.

Keywords: Biomass energy; Geothermal energy; Hydropower energy; Marine energy; Solar energy; Wind energy; Smart grid

\section{INTRODUCTION}

In remote areas, population density and power requirements are both very low, so the per capita costs of grid extension are often considerable. These areas usually remain unconnected to the power grid ("offgrid"). In recent years, renewable energy resources have come to be considered a viable alternative to the standard power supply in isolated communities, especially those in the rural areas [1]-[2]. Currently, the most widely used renewable energy resources are solar, wind, and hydroelectric power. However, the main disadvantages of such sources are intermittent and variable power output. One way of overcoming this problem is to build hybrid generators, such as wind-solar, wind-diesel, and solar-diesel systems [3][5]. This can help to alleviate the challenges of rural electrification.

The PV based hybrid system is considered a promising candidate for remote power generation due to the widespread availability of solar energy sources. One feasible scheme is the combination of solar and hydro energy resources, which takes advantage of their complementarily. One method of determining the effects of complementarily between solar and hydro energy systems has been evaluated [6]. A feasibility study of PV -hydro-wind hybrid system for rural electrification was undertaken some time ago [7]. Other papers have described the optimization processes suitable for sizing the hybrid system to the needed rural power supply [8]-[9]. In these systems, system modeling, simulations, and optimization using HOMER software were all used, including technical constraints. For the operation of PV-hydro hybrid systems, two previous reports proposed control 
strategies for reliable autonomous coordination and discussed involved system operation strategies [10][11]. In most cases, such hybrid systems also have diesel generators or battery banks, which are used as backup sources of electricity.

In the past, the majority research into the use of hybrid systems for the electrification of remote areas has focused on PV-wind, PV-diesel, and wind-diesel combinations, but studies of PV-hydro systems are relatively rare. For the work mentioned above based on PV -hybrid systems, regardless of whether they rely primarily on PV or hydro power, the capacity is always small, on the $\mathrm{kW}$-scale. Research into the stability of hybrid systems is insufficient. Drastic fluctuations of PV power output may occur, especially in large capacity hybrid systems, and this render the system more vulnerable.

This paper describes a grid connected solar-hydro autonomous hybrid system with a high penetration of PV power. The responses of the system to different scenarios, such as dramatic change in solar irradiance and forced outage of the PV subsystem, were determined. Based on this, a simulation of the system with a focus on stability was created using MATLAB software. On the basis of the simulation, reasonable measures and suggestions for stable and reliable operation are proposed.

\section{SYSTEM DESCRIPTION}

Fig. 1 shows the schematic diagram of the grid connected solar/hydro hybrid energy system. There are three main parts of the HES: hydro system, solar system, and grid. The hydro system is configured by hydro turbine driven synchronous generator with initial excitation requirement fulfilled by the excitation system. The PV system consists of PV array and DC/DC converter. The maximum power point tracking (MPPT) controller is employed to enhance the system efficiency and to control the DC/DC converter.

In the HES, the renewable hydro and solar system are considered as a primary source for supplying load demand and grid is used as an emergency purpose and surplus energy can also be return to the grid and extensive can be obtained. The control of all the renewable systems is provided through the independent controllers such as MPPT controller. To interface hydro/PV system and grid, the voltage levels must be the same. Hence, DC/DC converters are used in the HES system to link the common DC voltage of the renewable systems.

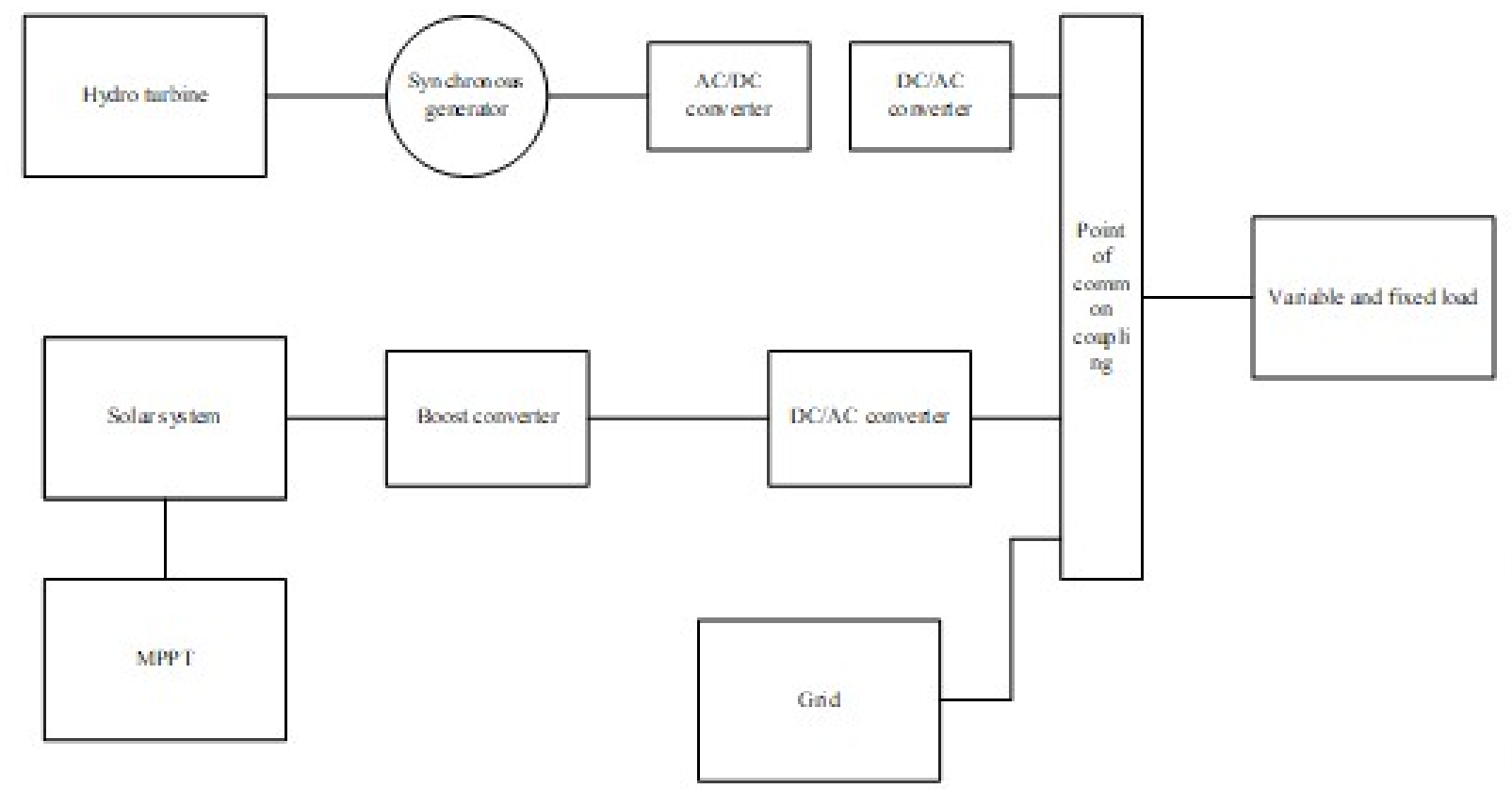

Fig. 1 Schematic of grid-connected solar/hydro based hybrid system 


\section{RENEWABLE ENERGY: BENEFITS, GROWTH, INVESTMENT AND DEPLOYMENT}

\section{A. Modelling of solar system}

The equivalent electrical circuit of a PV cell is given in Figure 2. It is a one diode model which is also known as the 5 parameter circuit. The cell can be modeled by other equivalent circuits as well; such as 7 parameters but the one diode model is the most commonly used circuit in the literature and the solution of the circuit is not as complicated as is the case in other models. The parameters in the circuit are; $\mathrm{I}_{\mathrm{D}}, \mathrm{I}_{\mathrm{L}}, \mathrm{I}_{\mathrm{SH}}, \mathrm{R}_{\mathrm{SH}}, \mathrm{R}_{\mathrm{S}}$, I and $\mathrm{V}$.
After substituting equations (2), (3), and (4) into equation (1), the equation takes the form of;

$I_{D}=I_{P H}-I_{0}\left[\exp \left(\frac{V+I R_{S}}{A V_{t}}\right)-1\right]-\frac{V+I R_{S}}{R_{S H}}$

\section{B. Modelling of synchronous generator}

The synchronous generator modelling is derived from an synchronous machine and reactive load generations. There active load generations can be undertaken by excitation capacitor or grid systems. The squirrel-cage induction machine of the mathematical modelling for $\mathrm{d}-\mathrm{q}$ frame, given as in this following equations:

\section{Electrical System \\ $v_{q s}=R_{s} i_{q s}+\frac{d \lambda_{q s}}{d t}+w \lambda_{\mathrm{ds}}$ \\ $v_{d s}=R_{s i_{d s}}+\frac{d \lambda_{q s}}{d t}-w \lambda_{\mathrm{qs}}$}

$0=R_{r}^{\prime} i_{q r}^{\prime}+\frac{d \lambda_{q r}^{\prime}}{d t}+\left(\bar{w}-w_{m}\right) \lambda_{d r}^{\prime}$

Fig. 2. Equivalent circuit of a solar cell

From the circuit;

$I=I_{P H}-I_{D}-I_{S H}$

$0=R_{r}^{\prime} i_{q r}^{\prime}+\frac{d \lambda_{d r}^{\prime}}{d t}-\left(w-w_{m}\right) \lambda_{q r}^{\prime}$

And

$\mathrm{I}_{\mathrm{PH}}$ (photo-generated current) is also called as $\mathrm{I}_{\mathrm{L}}$ (light current) which refers to direct current generated by photovoltaic effect. Whereas I is the output current of the cell.

From Shockley's diode equation;

$I_{D}=I_{0}\left[\exp \left(\frac{V+I R_{S}}{n V_{t}}\right)-1\right]$

Where;

$V_{t}=\frac{k T}{q}$

By Ohm's Law

$I_{S H}=\frac{V+I R_{S}}{R_{S H}}$

$$
\begin{aligned}
& \lambda_{q s}=L_{s} i q_{s}+L_{m} i^{\prime}{ }_{q r} \\
& \lambda_{q s}=L_{s} i_{d s}+L_{m} i_{d r}^{\prime} \\
& \lambda^{\prime}{ }_{q r}=L_{r}^{\prime} i^{\prime}{ }_{q r}+L_{m} i_{q s} \\
& \lambda_{d r}^{\prime}=L_{r}^{\prime} i^{\prime}{ }_{d r}+L_{m} i_{d s}
\end{aligned}
$$

Where:

$L_{s}=L_{l s}+L_{m}$

$L_{r}^{\prime}=L_{l r}^{\prime}+L_{m}$

Where:

$v \mathrm{dqs}, v \mathrm{dqr}$ are the stator and rotor voltages in the $\mathrm{d}-\mathrm{q}$ frame

$i \mathrm{dqs}, i \mathrm{dqr}$ are the stator and rotor currents in the $\mathrm{d}-\mathrm{q}$ frame

$\lambda \mathrm{dqs}, \lambda \mathrm{dqr}$ are the stator and rotor fluxes in the $\mathrm{d}-\mathrm{q}$ frame 
$R \mathrm{~s}, R \mathrm{r}$ are the stator and rotor resistances

$L 1$ s, $L \mathrm{lr}$ are the stator and rotor leakage inductances

$L \mathrm{~m}$ is the magnetizing inductance

$\omega$ is the arbitrary reference frame

Electromagnetic Torque

$T_{e}=\frac{3}{2} P\left\{\lambda_{d s} i_{q s-} \lambda_{q s} i_{\mathrm{ds}}\right\}$

Where :

Electromagnetic torque is denoted by $T \mathrm{e}$, and number of pole pair is denoted by $P$.

Excitation system for a self excited mode

$i_{q s}=i_{q l+} w q_{d c}+\frac{d q_{q c}}{d t}$

$i_{d s}=i_{d l}-w q_{q c}+\frac{\mathrm{dq}_{\mathrm{dc}}}{d t}$

And

$q_{q c}=c v_{q s}$

$q_{d c}=c v_{d s}$

Where:

$I \mathrm{dql}$ are the $\mathrm{d}$ line currents in the $\mathrm{d}-\mathrm{q}$ frame

$Q i$ dqc are the electric charge in the d-q frame
$C$ is the capacity of capacitor excitation

Mechanical System

$$
\frac{d W_{m}}{d t}=\frac{1}{2 H}\left\{T_{e}-F W_{m}-T_{m}\right\}
$$

Where:

$\omega \mathrm{m}$ is the rotor angle speed

In above equation, the machine acts as a generator if $T \mathrm{~m}$ is negative.

\section{SIMULATIONS AND RESULTS}

During operation, the power system may experience various kinds of small and large disturbances, some of which may pose a threat to the stable operation of the power system. Analysis of the simulation should be completed by system operators. Emergency control measures for common types of large disturbances should also be prepared in advance to ensure reliable operation of the grid.

The solar irradiance is variable and output of solar system depends on that. The variations in solar irradiance should not affect the power supply to the load. The load itself changing randomly and for this purpose a dynamic load is connected along with fixed load. The power provided by the solar and hydro system is shown in the following figures. The dynamic load power requirement is varied at time interval $0.0 \mathrm{sec}, \quad 0.2 \mathrm{sec}$ and $0.4 \mathrm{sec}$.

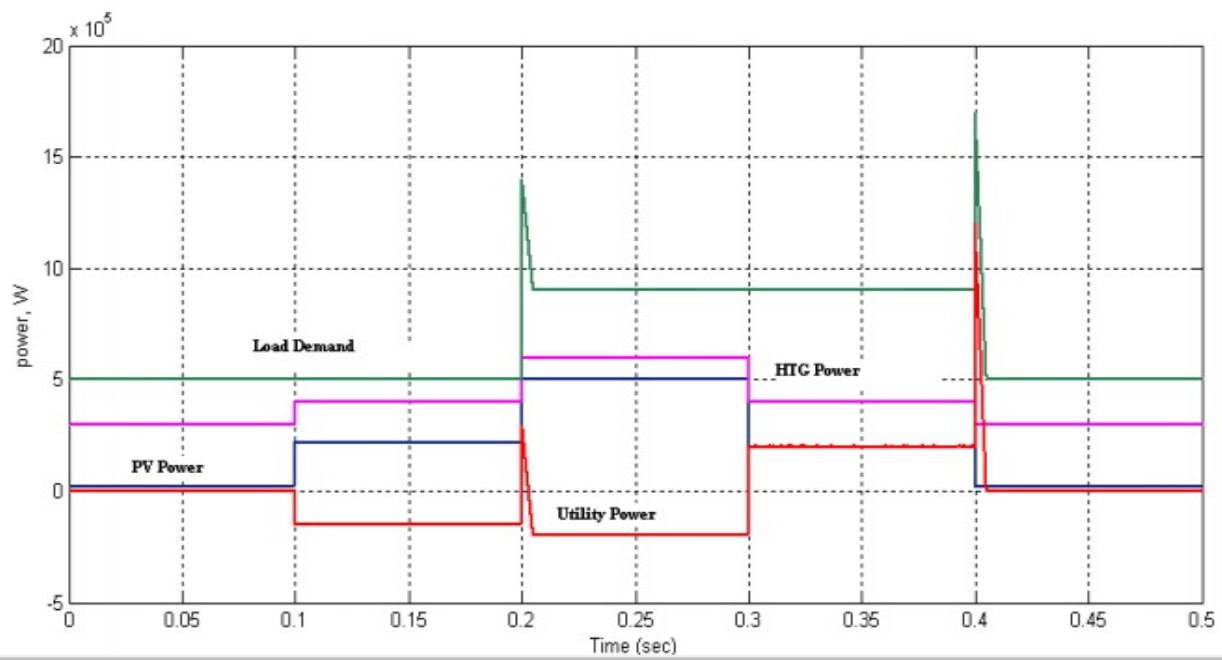

Fig. 3 Generated Powers from PV/HTG, Load Demand Grid Power 
International Journal of Trend in Scientific Research and Development (IJTSRD) ISSN: 2456-6470

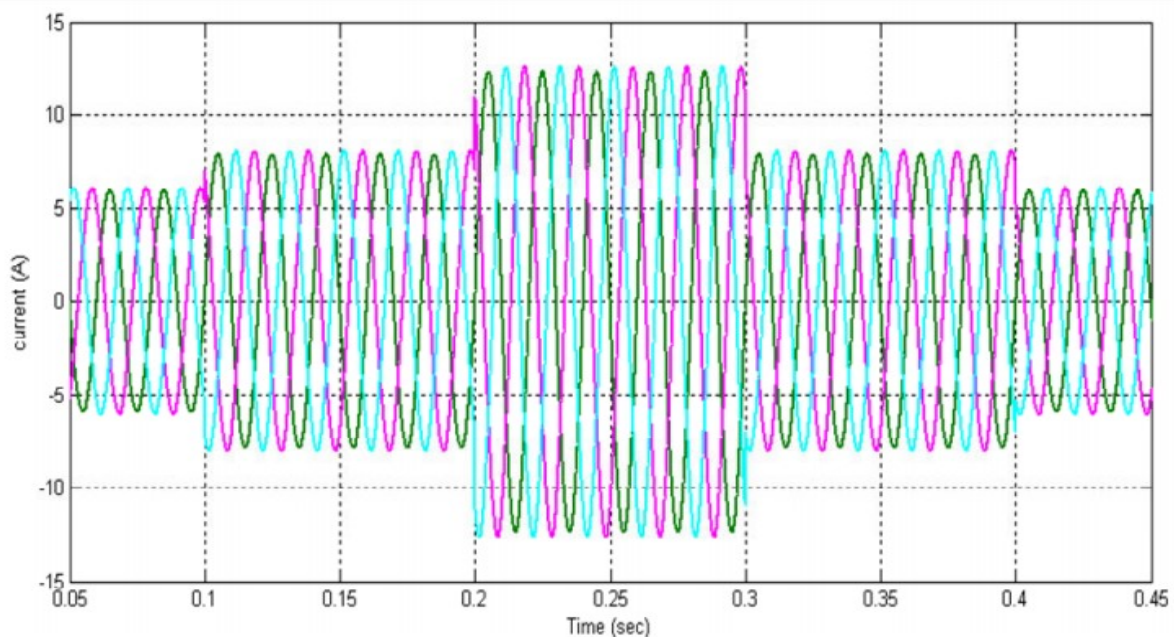

Fig. 4 Inverter Line current from HTG to the Load/Grid in the side (B)

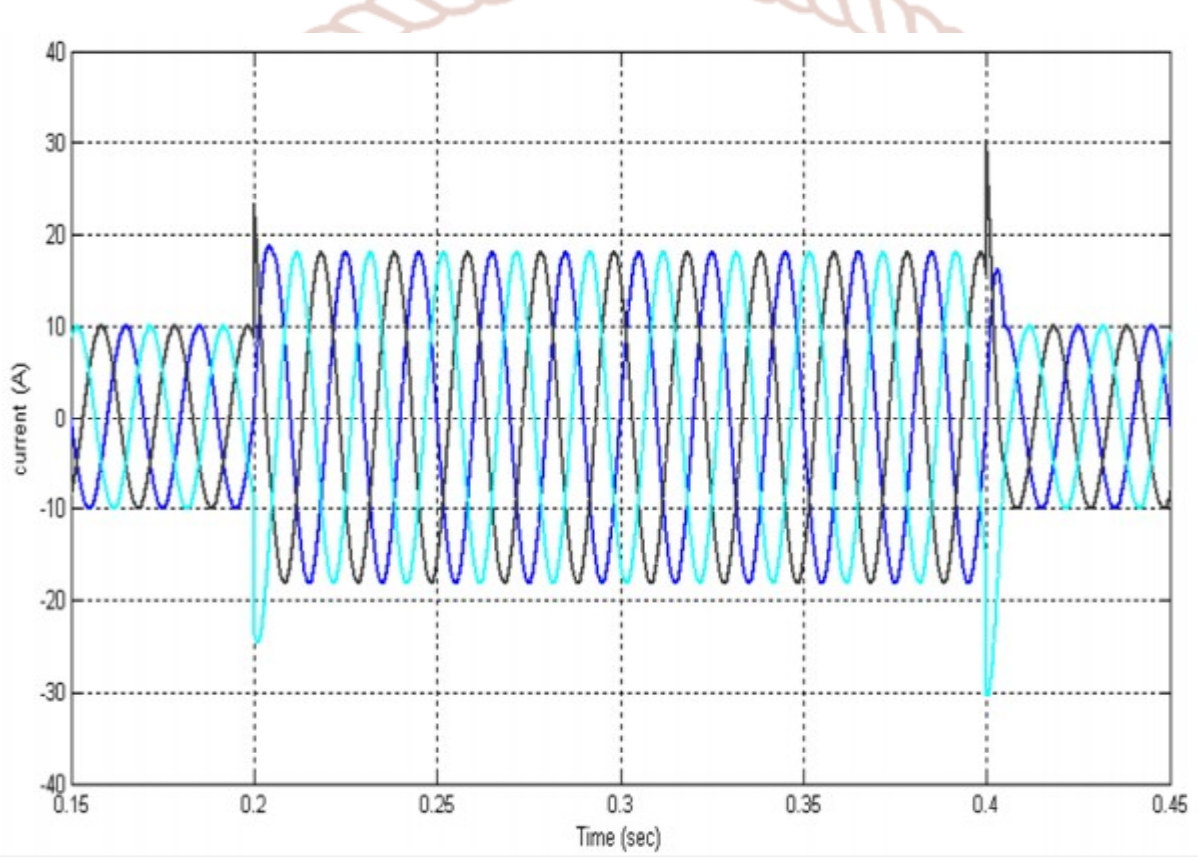

Fig. 5 Load Line Current in the side (C)

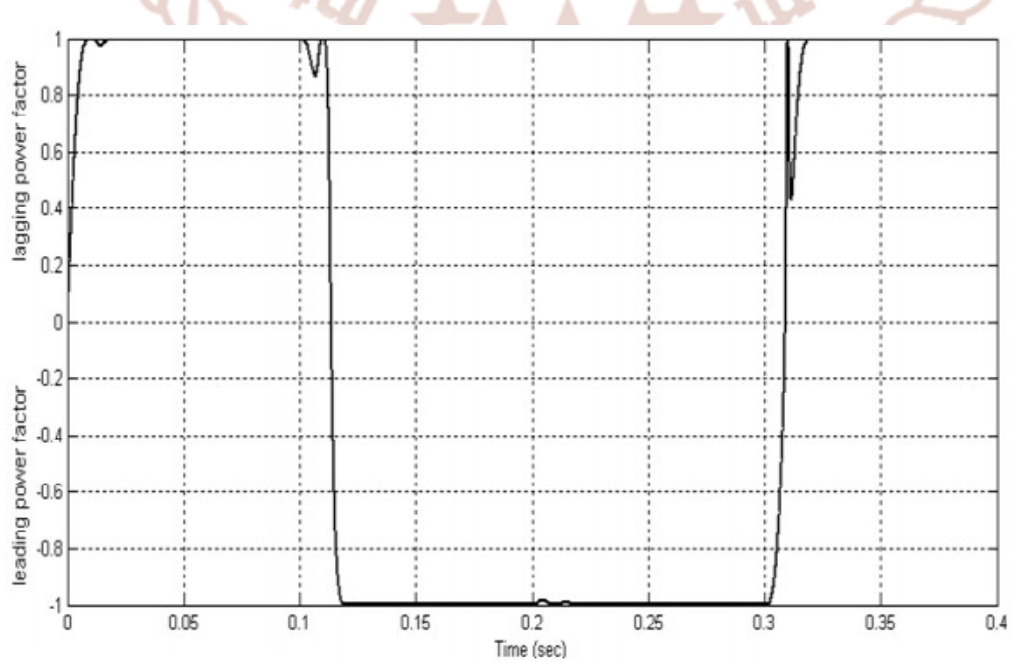

Fig. 6 Power Factor of the Grid for the Hybrid PV/HTG system 


\section{Conclusions}

A stability simulation of a solar-hydro grid-connected hybrid system was studied in this paper. First, the detailed MATLAB models of elements in the hybrid system, including PV subsystem, hydroelectric generating sets and grid were established. On this basis, a complete simulation model of the system was established. Several different simulations were performed for a typical system operation mode. The simulation results indicate that in the case of dramatic changes of solar irradiance, forced outage of a PV subsystem in order to ensure the stable operation of the grid, it is very important to take stability control measures. The automatic frequency control of hydro generator is another means of controlling stability. The following recommendations for maintaining and operating a stable hybrid system and for technical requirements of equipment involved were based on the results produced by the simulation.

\section{References}

1) H.H.El-Tamaly; Adel A. Elbaset Mohammed, "Modeling and Simulation of Photovoltaic/Wind Hybrid Electric Power System Interconnected with Electrical Utility," IEEE Conference on Power system, PP. 645-649, 2008.

2) Delimustafic D., Islambegovic J., Aksamovic A., Masic, S., "Model of a hybrid renewable energy system: Control, supervision and energy distribution," IEEE Conference, 2011, pp. 1081 1086.

3) Hang-Seok Choi, Y. J. Cho, J. D. Kim and B.H. Cho, "Grid-Connected Photovoltaic Inverter with Zero-Current-Switching”,
Conference on Power Electronics ICPE 2001, Oct. 2001, pp.251-255.

4) Arulampalam, Barnes, M., Engler, A., Goodwin, A. and Jenkins, N., 2004, "Control of Power Electronic Interfaces in Distributed Generation Microgrids," International Journal of Electronics, 91(9), pp. 503-523.

5) Kusakana, K.; Munda, J.L.; Jimoh, A.A "Feasibility study of a hybrid PV-micro hydro system for rural electrification", IEEE Conference, 2009, pp.1-5.

6) Mohibullah, M.; Radzi, A.M.; Hakim, M.I.A, "Basic design aspects of micro hydro power plant and its potential development in Malaysia" Power Energy conference 2004.

7) Gagan Singh and D.S. Chauhan, "Simplified Modeling of Hydraulic Governor-turbine for Stable Operation under Operating Conditions", International Journal of Engineering Research and Applications, Vol. 1, Issue 3, pp.478-482, Sept. 2011.

8) F. Blaabjerg, Remus Teodorescu and Marco Liserre, "Overview of control \& grid synchronization for distributed power generation systems", IEEE transaction on Industrial Electronics, Vol. 53, pp. 500-513, Oct- 2006.

9) Nehrir, M.H. et al., "A Review of Hybrid Renewable/Alternative Energy Systems for Electric Power Generation: Configurations, Control, and Applications", IEEE transaction on Sustainable Energy, Vol. 2, No. 4, PP. 392-403, Oct. 2011. 